Personality Change: Longitudinal Self-Other Agreement and

Convergence with Retrospective-Reports

Joshua R. Oltmanns ${ }^{1}$, Joshua J. Jackson ${ }^{2}$, and Thomas F. Oltmanns ${ }^{2}$

University of Kentucky ${ }^{1}$, Washington University in St. Louis ${ }^{2}$

(C) 2019, American Psychological Association. This paper is not the copy of record and may not exactly replicate the final, authoritative version of the article. Please do not copy or cite without authors' permission. The final article will be available, upon publication, via its DOI: $10.1037 /$ pspp0000238

Author's note:

Research reported in this publication was supported by the National Institute On Aging and the National Institute of Mental Health of the National Institutes of Health under Award Numbers F31AG055233, RO1-AG045231, and RO1-MH077840. The content is solely the responsibility of the authors and does not necessarily represent the official views of the National Institutes of Health. Data for this project have been presented previously by the first author at the Society for Personality and Social Psychology in Atlanta, GA, and at the International Society for the Study of Personality Disorders in Montreal, Quebec.The authors would like to thank members, past and present, of the St. Louis Personality and Aging Network and Michael Boudreaux and Thomas Widiger for helpful comments.

Correspondence should be addressed to Joshua R. Oltmanns, Department of Psychology, University of Kentucky, 111-D Kastle Hall, Lexington, KY, 40506. Email: jroltmanns@uky.edu 


\begin{abstract}
The research literature on personality development is based mostly on self-report studies and on samples in younger adulthood. The present multi-method study examines self-other agreement on longitudinal personality change and convergence between self- and informant-reports of longitudinal and retrospective personality change in older adulthood. It provides a rare validation test of longitudinal measurements of personality change. A representative community sample of 1,630 older adults $(M$ age $=62.5)$ and their informants completed self- and informant-personality assessments across three waves that were on average 6.5 years apart. Self- and informant-reports of retrospective personality change were collected at the third wave. Latent growth modeling was used to examine longitudinal personality change, longitudinal self-other agreement on personality change, and convergence between longitudinal and retrospective personality change in each five-factor model domain. Older adults in the present study reported less change than has been found in younger samples; however, both self- and informant-reports indicated declines in extraversion. Results showed strong self-other agreement on longitudinal personality change in all five-factor model domains, moderate correspondence between longitudinal and retrospectivereports of change within-method (i.e., within self- or informant-report), modest self-other agreement on retrospective-reports, and little association between longitudinal and retrospective change across-method (i.e., between self- and informant-reports). Findings provide validation evidence for both longitudinal and retrospective assessments of personality change, indicate that informants provide unique perspectives on personality change, and could have potentially important implications for research, assessment, and clinical settings.
\end{abstract}

keywords: personality change; five-factor model; aging; informant; agreement 


\section{Personality Change: Longitudinal Self-Other Agreement and \\ Convergence with Retrospective-Reports}

"The analysis of everyday change judgments has remained the province of speculation, with change impressions still being regarded as having a largely self-evident character, one that can be understood without reference to an empirical base.” Linda Silka (1989)

Personality is a powerful predictor of important life outcomes such as physical and mental health, divorce, occupational attainment, and mortality (Ozer \& Benet-Martinez, 2006; Roberts, Kuncel, Shiner, Caspi, \& Goldberg, 2007). Empirical evidence also suggests that personality changes across the lifespan (Roberts, Walton, \& Viechtbauer, 2006) and a growing body of research suggests that personality change predicts important life outcomes (Human et al., 2013; Mroczek \& Spiro, 2007; Siegler et al., 2003; Turiano et al., 2011). Informant-reports of personality have demonstrated incremental validity over self-reports in personality assessment and in the prediction of important life outcomes (Connolly \& Ones, 2010; Fiedler, Oltmanns, \& Turkheimer, 2004; Jackson, Connolly, Garrison, Leveille, \& Connolly, 2015), and may be useful in gathering information about personality change. Similarly, retrospective-reports of personality change (i.e., personality assessments made at one point in time asking a person to report on how their personality has changed across time) could have important utility in clinical and assessment settings - and offer one of the few ways to validate longitudinal findings of personality change.

Most research on longitudinal personality change (i.e., change measured prospectively across multiple time points) and retrospective-reports of personality change has relied exclusively on self-report questionnaires. As a result, little is known about longitudinal informant-reported change and self-other agreement on personality change. Furthermore, few retrospective studies have used longitudinal designs to examine convergence between longitudinal and retrospective-reports of change, and these studies have been limited by single- 
item measures of personality change, measurement of change across only two time points, and exclusive reliance on self-report questionnaires. The present study addresses prior limitations and uses multiple methods (self- and informant-reports) to examine personality change, self-other agreement on personality change, and the convergence between longitudinal and retrospectivereports of personality change.

\section{Personality Change and Life Outcomes}

Across early adulthood, on average, people appear to increase in extraversion, agreeableness, and conscientiousness, and decrease in neuroticism, an effect known as the “maturity principle” (Roberts, Wood, \& Caspi, 2008; Roberts et al., 2006). Rank-order consistency of personality traits (i.e., how consistent people are in their rank on a personality trait compared to others across time) also increases from adolescence to adulthood and stays consistent into later middle-age (Roberts \& DelVecchio, 2000; Specht, Egloff, \& Schmukle, 2011). From later middle-age into old age, there appear to be mean-level declines in extraversion, conscientiousness, and openness, and increases in neuroticism (Lucas \& Donnellan, 2011; Roberts et al., 2006; Specht et al., 2011), and a drop in rank-order consistency, an effect that has been called the "end of maturity" (Lucas \& Donnellan, 2011). However, research on personality change from later middle-age into old age is rare compared to studies from adolescence to younger adulthood. In the present study, we examine personality change in older adulthood, first because most personality change research to date has been from adolescence to younger adulthood and second because prior research shows older adulthood is a time when personality may begin to change again in the transition to old age (Roberts et al., 2006).

Studies using longitudinal personality assessments (i.e., personality assessments collected at multiple time points), have demonstrated the importance of personality change to health 
outcomes (e.g., Jackson, Weston \& Schultz, 2017). For example, significant increases in neuroticism increase the risk of death by heart attack in men (Mroczek \& Spiro, 2007), changes in openness predict substance abuse (Turiano et al., 2012), changes in neuroticism predict general mental health problems (Magee, Heaven, \& Miller, 2013), changes in conscientiousness are associated with changes in physical health (Takahashi, Edmonds, Jackson, \& Roberts, 2013), and global personality change predicts greater metabolic syndrome (e.g., sedentary lifestyle, abdominal adiposity, and high blood pressure) (Human et al., 2013). The above findings all relied on self-report methodology. However, several unique studies incorporating informantreports of personality have found that informant-reports can be particularly useful for identifying potential personality change associated with the onset of cognitive decline (for example decreases in extraversion, openness, agreeableness, and conscientiousness, and increases in neuroticism; Balsis, Carpenter, \& Storandt, 2005; Benedict, Priore, Miller, Munschauer, \& Jacobs, 2001; Chatterjee, Strauss, Smyth, \& Whitehouse, 1992; Duchek, Balota, Storandt, \& Larsen, 2007). This evidence suggests that if retrospective-reports of personality change are valid, they are a potentially useful tool for improving clinical health assessment of personality and related risk factors, and that informant-reports may be particularly critical at times. For instance, they may be especially important for personality assessment with older adults, who are at higher risk for experiencing cognitive decline. This is the age group of the target participants in the present study.

\section{Self-Other Agreement on Personality Change}

Self-other agreement on personality traits has been of interest to researchers particularly since it was used as validation evidence to support that personality traits exist (i.e., "consensual validation"; McCrae \& Costa, 1987; Norman, 1963). Agreement on personality traits depends on 
several factors (Funder, 1995). One such factor is the specific personality trait that is being assessed. Self-other agreement is higher on extraversion and conscientiousness traits, relatively lower on openness traits, and particularly lower on neuroticism and agreeableness traits (Connelly \& Ones, 2010). It is thought that extraversion and conscientiousness show higher selfother agreement because they are more behavioral and observable to both the self and others, while neuroticism traits in particular are more internal and affective, and therefore more noticeable to targets themselves (i.e., self-reports) than to observers (John \& Robins, 1993; Vazire, 2010). Self-other agreement on personality increases with closeness (Conelly \& Ones, 2010), and thus levels of agreement also depend on the nature of the relationship between the target and the informant. Closeness provides more occasions to notice and then accurately judge a target's personality. Romantic partners who have been together for a longer period of time tend to show higher levels of self-other agreement, especially for traits lower in observability such as neuroticism (Connelly \& Ones, 2010).

The tendency for self-other agreement to be higher on extraversion and conscientiousness has been replicated often both cross-sectionally (Connelly \& Ones, 2010) and across development (Göllner et al., 2017, Luan et al., 2017). Cross-sectional self-other agreement has been shown to increase from adolescence to young adulthood, mirroring the maturity principle of personality development (Rohrer, Egloff, Kosinski, Stillwell, \& Schmukle, 2018). However, there have been fewer studies specifically on self-other agreement on personality trait change, and to our knowledge no studies in older adulthood. Naturally, because there are few studies examining personality change across time using informant-reports, we know little about self-other agreement on change. McCrae (1993) examined raw change scores between self- and informant-reports across several years in two relatively small samples $(n=136$ 
and $n=46$, respectively). There was a small, but significant, association between self- and spouse-neuroticism raw change scores in the first sample $(r=.16)$, but no significant agreement on raw change scores for any of the other five-factor model (FFM) domains. In the second sample, there was not statistically significant agreement on any of the FFM domains. McCrae concluded that, "these analyses provide no evidence that change scores in self-reports or [informant] ratings reflect anything more than error of measurement" (p. 583). Watson and Humrichouse (2006) found, similarly, that 150 newly married couples tended not to agree on personality changes across a two-year period, also using change scores and reliable change indices. They found small but significant correlations on change in conscientiousness and neuroticism. The findings from these two studies together indicate that while people do tend to agree on personality cross-sectionally, targets and their informants tend not to agree on personality trait change across time. However, both of these studies were limited by the use of smaller samples and reliance on two time points. Furthermore, the newlywed sample utilized by Watson and Humrichouse (2006) was influenced by the "honeymoon effect," in which partners provided more well-adjusted informant-ratings at baseline which faded more quickly than would be found otherwise. The present study uses bivariate latent growth modeling (Bollen \& Curran, 2006; Newsom, 2015) to examine self-other agreement on latent personality change factors. A larger sample of people was followed across three time points, which may increase the power to detect change (Raudenbush \& Bryk, 2001). We are not aware of any previous studies examining self-other agreement on personality change using latent growth modeling.

\section{Convergence Between Longitudinal and Retrospective-Reports}

Two methods are used to examine personality change in the present study: Longitudinalreports of change, which provide the ability to examine change statistically based on personality 
assessments completed across multiple time points, and retrospective-reports of change, which are personality assessments completed at one time point asking examinees to report how they (or a target participant, in the case of informant-reports) have changed across a specified period of time. Tests of the convergence between retrospective- and longitudinal-reports of personality change could provide information about the "accuracy" of retrospective reports of change. Alternatively, they could be conceptualized as validation evidence of longitudinal findings on personality change. If the two methods converge, it would indicate that they measure a similar personality change construct. Cross-sectional retrospective-reports of FFM personality trait change have shown that people concurrently self-report higher levels of agreeableness and conscientiousness, but lower levels of extraversion, than they retrospectively report (Fleeson \& Heckhausen, 1997; Handel, Kimhi, \& Leviatan; 1983; Quoidbach et al., 2013; Ryff, 1982). However, the cross-sectional and self-report methodologies employed in these studies make it impossible to know whether retrospective-reports of personality change actually converge with longitudinal personality change. Further, to our knowledge the convergence of retrospective informant-reports of change with longitudinal informant-reports of change has not been examined in any previous studies.

Three empirical studies have been conducted previously on the convergence of retrospective and longitudinal personality change. Woodruff and Birren (1972) found that 54 middle-aged adults reported their personalities to have been less well-adjusted as undergraduate students than they had actually described their personalities to have been at the time. Two more recent studies have directly compared the correspondence between retrospective self-reports of personality change and personality change assessed via self-reports measured longitudinally across two time points (Herbst, McCrae, Costa, Feaganes, \& Siegler, 2000; Robins, Noftle, \& 
Trzesniewski, 2005). Both studies (one with 2,242 middle-aged adults [Herbst et al., 2000] and the other with 290 college students [Robins et al., 2005]) found modest, or low effect-size (Cohen, 1992), relationships between retrospective personality change reports and residual change scores across the two time points. In terms of the percentage of participants reporting change, college students reported more change and more "positive" personality change (i.e., decreases in neuroticism and increases in the other four FFM domains) than middle-aged adults. On average across the FFM domains, middle-aged adults reported they had stayed the same $68 \%$ of the time, whereas college students reported they had stayed the same $37 \%$ of the time. On average, college students also saw themselves as experiencing more positive personality changes than middle-aged adults ( $49 \%$ versus $25 \%$ ), but both groups reported approximately the same percentage of negative change, on average, across the FFM domains (i.e., increases in neuroticism and decreases in the other four domains): $14 \%$ for young adults and $13 \%$ for middleaged adults (Herbst et al., 2000; Robins et al., 2005). Herbst et al. also found that people who were more open and neurotic tended to report more global personality change.

\section{Limitations of Prior Longitudinal Retrospective Studies}

Prior studies examining the convergence between retrospective and longitudinal personality change have been limited by their exclusive reliance on self-reports, assessment of personality at only two time points, and use of single-item measures of retrospective change (i.e., one item per domain, or one item for global personality change). Herbst and colleagues (2000) measured global personality change with one item, on which participants were asked to indicate, overall across time, whether they had "(a) changed a good deal in your personality, (b) changed a little in your personality, or (c) stayed pretty much the same in personality" (p. 381). Retrospective FFM domain change, specifically, was also assessed with one item per domain. 
For example, in the domain of extraversion, participants were asked, "compared to how you were six years ago, how lively, cheerful, and sociable are you now?" (p. 381), and responded with one of three options: more, less, or same. Robins and colleagues (2005) also measured retrospective personality change with one item per FFM domain. For example, in the extraversion domain, participants were asked to rate how they had changed in being "talkative, outgoing, enthusiastic" (p. 497) on a scale from 1 (decreased) to 5 (increased), with a neutral option in the middle. Although it is undesirable to add burden onto participants in longitudinal studies in the form of additional items, reliance on single-item measures is potentially a serious psychometric limitation. Multi-item assessments are more reliable and reduce the amount of error included in the measure (Furr \& Bacharach, 2007; Haynes, Smith, \& Hunsley, 2011). Reduction in reliability, and increase in error, constrains the size of potential associations that can be found between variables (Haynes et al., 2011). Thus, the maximum convergence prior studies could have found between retrospective-reports of change and longitudinal change might have been modest (which is what was found).

Informant-reports of personality provide unique information that is at times incremental to that of self-reports. Studies suggest that self-reports are better for assessment of personality traits that are less observable to others, but that informants can provide better judgments of personality traits that are more observable (Funder, 1995; Vazire, 2010). People also might display a retrospective bias centered on ratings related to the self, but not when rating others (John \& Robins, 1994; Wilson \& Ross, 2001), and may be limited by an inability to perceive self-behaviors neutrally. There is evidence that people sometimes derogate prior selves and prior levels of skills and emotions and report better improvement for themselves than for peersperhaps in order to feel better about themselves in the present (Levine \& Safer, 2002; Conway \& 
Ross, 1984; Ross \& Wilson, 2003). Self-other agreement on personality traits is often only moderate (Connelly \& Ones, 2010), yet informant-reports of personality augment behavioral ratings made by observers (Kolar, Funder, \& Colvin, 1996), self- and interview-ratings (Oltmanns \& Turkheimer, 2006), ratings of cognitive impairment (Ducheck, Balota, Storandt, \& Larsen, 2007), and the prediction of life outcomes (Benedict et al., 2001; Fiedler et al., 2004; Jackson, Connolly, Garrison, Leveille, \& Connolly, 2015). These findings suggest that the unique information provided by informants contains valid information that is absent in selfreport. Stepping outside of self-report in the assessment of retrospective and longitudinal personality change might be an important way to expand our understanding of personality change.

Finally, prior studies examining the convergence of retrospective and longitudinal reports of change have been limited by reliance on personality assessments made at only two time points. Statistical evidence demonstrates that the addition of even a third time point in the measurement of change significantly improves the measurement accuracy of change (Raudenbush \& Bryk, 2001). Similar to the importance of using multiple items to assess retrospective change to reduce error and possible attenuation, the addition of a third assessment time point would reduce error in longitudinal measurement of personality change.

\section{The Present Study}

The present study is a longitudinal investigation of self-other agreement on personality change and of convergence between self and informant longitudinal and retrospective personality change measurements. Self- and informant-reports of personality (used to measure longitudinal personality change) were collected at three time points, across an average total of 6.5 years, from a representative sample of 1,630 adults in later middle-age. Self-other agreement was examined 
using the 240-item NEO-PI-R (Costa \& McCrae, 1992) and retrospective personality change in the FFM domains was assessed using 30 items, which boosts reliability and potential for statistical association of variables (Furr \& Bacharach, 2007). Personality was assessed at three time points - increasing the power to measure change and the precision of parameter estimatesand we used latent growth modeling to extract latent intercept and slope factors from the longitudinal personality markers (Bollen \& Curran, 2006; Jackson \& Allemand, 2014; Newsom, 2015; Rogosa, Brandt, \& Zimoski, 1982). The latent slope factor can be interpreted as "growth," or longitudinal change in personality across the study. In bivariate growth models incorporating both self- and informant-reports, the growth factors can be correlated to assess self-other agreement on longitudinal change. In models including the retrospective reports, the growth factors can be regressed on retrospective change (Curran, Bauer, \& Willoughby, 2004; Duncan \& Duncan, 2004), providing an estimate of the convergence between retrospective change and longitudinal change. Further, associations between intercepts (i.e., initial baseline status) and slopes can be examined within and across-methods (i.e., self- and informant-reports). In the present study, we interpret effect sizes according to Cohen's (1992) guidelines.

The present study adds to the literature on personality change through several contributions: 1) Longitudinal studies of change using informant-reports are rare. The present study is important in its use of a multi-method investigation of personality change, and its ability to examine self-other agreement on personality change. Does self-other agreement on longitudinal change in personality mirror cross-sectional self-other agreement on personality? To our knowledge this is the first study to examine, specifically, self-other agreement on latent longitudinal personality change factors. 2) Similarly, to our knowledge this is the first study to examine self-other agreement on retrospective personality change. Do targets and informants 
agree on how they believe a target has changed across time? 3) The present study contributes to the validation of longitudinal personality change measurements. While changes in personality traits have been calculated in countless longitudinal studies, there are few ways to validate what that change indexes. Convergence between longitudinal and retrospective change (i.e., explicit questionnaires regarding personality change) would support the validity of longitudinal personality change measurements. 4) Similarly, the present study will provide preliminary findings on whether people are aware of their personality change retrospectively. That is, do retrospective reports on personality change align with change across time? 5) The present study is also novel in its use of a large and representative community sample of older adults.

It was expected that a smaller percentage of the present sample would report personality change, compared to previous studies of younger adults, because reports of personality change have been found to decrease with age (Handel et al., 1983; Quoidbach et al., 2013). However, we expected that retrospective-reports of change would be in a positive direction (e.g., decreases in neuroticism, increases in agreeableness and conscientiousness), as has been found previously in middle-aged adults (Herbst et al., 2000). It was also expected that longitudinal change would be at least modestly associated with retrospective change, as has been found in prior research (Herbst et al., 2000; Robins et al., 2005). We expected that unique information would be gained about personality change from informant-reports, and that informant-reports would be more reliable and predictive of change than self-reports, as has been found previously in studies regarding the internal consistency and criterion validity of informant-reports compared to selfreports (Balsis, Cooper, \& Oltmanns, 2015; Connelly \& Ones, 2010; Clifton et al., 2005; Jackson et al., 2015; Oltmanns \& Turkheimer, 2006). We had no a priori hypotheses regarding self-other agreement across time, but prior findings indicated that although cross-sectional self-other 
agreement is moderate, self-other agreement on longitudinal change is modest or not statistically significant. Outside of our general hypotheses, the analyses reported here are otherwise exploratory.

As these data are from an ongoing NIH-funded longitudinal study of personality and health in older adults, portions of the longitudinal personality data have been published previously (a list of articles that have presented portions of these data is included in the supplemental materials). However, this project examines personality change across three waves of data collection, examines an entirely different research question, uses entirely different statistical analyses, and focuses on an instrument for which data were collected solely for this study (retrospective personality change) and have not been reported previously. The present study was approved by the Washington University institutional review board \#201102523, Titled "Personality and Health in Later Life."

\section{Method}

\section{Participants}

Participants were a representative sample of 1,630 older adults from the St. Louis Personality and Aging Network (SPAN) longitudinal study of personality and health (Oltmanns, Rodrigues, Weinstein, \& Gleason, 2014). Each participant nominated one informant who "knew them best" to complete informant-report questionnaires about him or her (these informants included $50 \%$ romantic partners, $27 \%$ other family members, $22 \%$ friends, and $2 \%$ other). Personality data for the present study were collected at baseline (Wave 1), and 2.5 and 5-year follow-up assessments resembling the baseline assessment (Waves 2 and 3). Time across the three waves was 6.5 years $(S D=0.6$ years $)$, on average. The questionnaire battery was administered in person, online, or on special occasions (e.g., if the participant had a special 
disability) over the phone and took approximately 1.5 hours to complete. Participants were compensated $\$ 60$ for their time. At Wave 1, participants were on average 62.5 years old $(S D=$ 2.8 years) and were $56 \%$ female. Racial and ethnic backgrounds were representative of the St. Louis area and consisted of $68 \%$ white/Caucasian, $30 \%$ black/African-American, $0.2 \%$ East Asian/Pacific Islander, 0.3\% Middle Eastern, 0.1\% Native American, 0.7\% Biracial, and 1.0\% other. Two percent reported that they were of Hispanic/Latin descent.

Mean differences between completers and non-completers were compared on the FFM scales for both self- and informant-reports: According to self-reports, participants who completed all three data collections were less neurotic $(t[1,611]=2.61, p=.009, d=.17)$ more open $(t[1,611]=2.26, p=.024, d=.15)$, agreeable $(t[1,611]=3.37, p=.001, d=.22)$, and more conscientious $(t[1,611]=2.59, p=.010, d=.17)$ than dropouts (i.e., those who missed 2 waves) and according to informant-reports targets were more open $(t[1,463]=2.06, p=.039, d=.15)$, agreeable $(t[1,463]=2.88, p=.004, d=.20)$, and conscientious $(t[1,463]=3.34, p=.001, d=$ .23). These small mean differences (according to Cohen's [1992] guidelines) are comparable to those found by Ludkte et al. (2011) and Specht et al. (2011) who used latent growth modeling with large samples to examine personality change over time.

A group of participants $(n=273)$ completed their second wave on average 1.6 years later than the others due to a gap in funding and data collection in the parent study. Ninety-four targets also had a change of informant across the study. Dummy variables were created to account for these two considerations and were included in models including these and other covariates that are described in the results.

\section{Measures}

NEO-PI-R (Costa \& McCrae, 1992). 
The 240-item NEO-PI-R is a measure of the FFM of personality. The five domains each include six 8-item facet scales. Items are rated from 0 (strongly disagree) to 4 (strongly agree). It was completed by both target participants and informants describing the target participants' personalities at all three assessment waves. Domain scale descriptive statistics and internal consistencies are provided in Table 1. Facet scale reliabilities ranged from $\alpha=.56$ (self-report baseline E5 Excitement-Seeking) to $\alpha=.90$ (informant-report wave 3 A1 Trust), with a median of $\alpha=.76$. Thirty NEO-PI-R items corresponding to the retrospective change scale items (described below) were used in the retrospective analyses (six items per scale). Descriptive statistics and internal consistencies for only these items are also presented in Table 1. One thousand six hundred and twelve participants completed the NEO-PI-R at Wave 1, $n=1,267$ at Wave 2, and $n=1,061$ at Wave 3. One thousand four hundred sixty-five informants completed the NEO-PI-R items at Wave $1, n=1,053$ at Wave 2, and $n=854$ at Wave 3 . Retrospective Change Scales.

Domain-level retrospective personality change scales were created using 30 items from the NEO-PI-R (six per FFM domain). Items were chosen for ideal interpretability in the context of change. Items chosen from neuroticism and extraversion tapped five facets each (anxiety, angry hostility, depression, self-consciousness, and vulnerability from neuroticism; and warmth, gregariousness, assertiveness, activity, and positive emotions from extraversion) and items from openness, agreeableness, and conscientiousness tapped four facets (aesthetics, actions, ideas, and values from openness; trust straightforwardness, altruism, and compliance from agreeableness; and order, dutifulness, achievement-striving, and self-discipline from conscientiousness). Four items were adjusted to remove reverse-scoring (three from neuroticism, one from conscientiousness). 
One thousand fifty-four target participants and 835 informants completed the self- and informant-report retrospective change scales at Wave 3, respectively. Participants were provided the following instructions:

"Instead of describing how you see yourself now, we would like for you to tell us to what extent you believe you have changed on these personality traits since your first personality assessment with us. For each statement, imagine if/how you have changed on that trait. For example, if the item was 'Funny', you would tell us on a 1-5 scale how you have increased (become 'Funnier') or decreased (become less 'Funny'), or if you have stayed the same (stayed equally 'Funny')."

Interviewers explained the directions (in person) to target participants before they completed the questionnaire. Each of the 30 items were then rated from 0 (decreased a lot) to 4 (increased a lot). Detailed directions were provided to informants in their questionnaire battery online or in a paper packet (provided in Appendix A).

Two items were deleted from the openness change and corresponding abbreviated NEOPI-R scales because the change-adapted items were largely uncorrelated with the other openness change items (one from the actions facet and one from values facet). The openness scales thus consisted of four items instead of six. Their deletion increased the openness change scales' alpha statistics by greater than .10. Internal consistency estimates and percentages of reported retrospective change are provided in Table 1.

\section{Results}

Descriptive statistics for the self- and informant-report retrospective change variables are displayed in Table 1 . On average, $24 \%$ percent of target participants and $22 \%$ of informants described target participants as changing (i.e., increasing or decreasing) across the FFM domains. 
On average, $14 \%$ of targets and $12 \%$ of informants described targets as changing in "positive" directions (i.e., decreasing in neuroticism, and increasing in extraversion, openness, agreeableness, and conscientiousness) across the FFM domains. Nine percent of targets and 9\% of informants described targets as changing in "negative" directions (i.e., increasing in neuroticism, and decreasing in extraversion, openness, agreeableness, and conscientiousness), on average, across the FFM domains. Self-reports tended to deviate more from the mean than informant-reports, notably in neuroticism, openness, and agreeableness. It is also apparent that there was non-normality in the data and, as a result, the statistical models containing these variables were fit using robust maximum likelihood estimation. The final column of Table 1 demonstrates that the internal consistency estimates were noticeably higher for the informantreports compared to the self-reports in extraversion and agreeableness.

Descriptive statistics for the NEO-PI-R scales are provided in Table 2. Informant-reports demonstrated higher internal consistency than self-reports, especially for agreeableness and conscientiousness. The internal consistency of the self-report NEO-PI-R agreeableness items that corresponded directly with the retrospective change items was particularly low (median $\alpha=.50$ ). Correlations among all study variables are included in Table S1 of the supplemental materials. Self-other agreement on the observed full NEO-PI-R domain scales ranged from $r=.36$ (Wave 2 and Wave 3 agreeableness) to $r=.58$ (Wave 3 openness), with a median of $r=.45$. Also of interest was that self-other correlations between the observed retrospective change scales ranged from $r=.06$ (self-informant agreement on retrospective agreeableness) to $r=.18$ (self-informant agreement on retrospective neuroticism), with a median of $r=.14$. All self-other agreement correlations on retrospective change were significant $(p<.05)$ except for on agreeableness. Thus, 
on the observed variables, self-other agreement on FFM personality at each wave was moderateto-large and self-other agreement on retrospective change was low (Cohen, 1992).

To replicate prior findings regarding the convergence of retrospective change with longitudinal change (c.f. Herbst et al., 2000; Robins et al., 2005), residual change scores were created by regressing Wave 3 personality scales on Wave 1 personality scales, saving the standardized residual scores, and correlating these residual scores with retrospective change (results displayed in Table 3). Residual change scores were significantly correlated with retrospective change scores at small effect sizes (i.e., <.30; Cohen, 1992) across both self- and informant-reports and in all FFM domains, replicating the findings of Herbst et al. (2000) and Robins et al. (2005), with the exception of self-reported agreeableness, which was not statistically significant ${ }^{1}$.

\section{Measurement Invariance}

Prior to estimating latent growth models, it should be demonstrated that measurement models are invariant across time. We completed a series of tests imposing increasingly restrictive constraints on the models. We examined measurement invariance at the facet level for the full NEO-PI-R and also for models at the item level using only the 30 NEO-PI-R items that were used in the retrospective analyses. For the analyses using the full NEO-PI-R, the 30 facet scales were used as indicators with the six observed facet scores per domain loading on each latent domain score. For the analyses using only the 30 NEO-PI-R items corresponding with the retrospective change questionnaire, each of the six items per domain were specified to load on latent domain variables. First, loadings on the latent factors were constrained to be equal across time (weak invariance), second the intercepts were specified to be equal across time (strong

\footnotetext{
${ }^{1}$ Results were interpreted by effect size where possible. An alpha value of .05 was used for all significance tests, but exact $p$-values for all key tests are provided.
} 
invariance), and finally the residual variances were constrained to be equal across time (strict invariance) (Stark, Chernyshenko, \& Drasgow, 2006). At each step, if model fit was not different, then invariance was assumed. We followed guidelines by Chen (2007) to judge differences between models with increasing restrictions: A change of .01 in CFI between less restrictive to more restrictive models, supplemented with a change of either .015 of RMSEA or .030 in SRMR would indicate a significant difference. For strong and strict invariance, a change of .010 in SRMR was used as a supplement (instead of .030), per Chen (2007). According to these criteria, all models achieved strict invariance. Model fit indices in all measurement invariance tests are presented in the supplemental materials.

\section{Self-Other Agreement on Longitudinal Personality Change}

Latent growth models (Bollen \& Curran, 2006; Newsom, 2015) were fit using the lavaan package (Rosseel, 2012) in R statistical software (R Core Team, 2013). Full-information maximum likelihood estimation was used to account for missing data, as was used by Ludtke et al. (2011) and Specht et al. (2011) who used latent growth models to examine personality change with similar levels of missing data. Five bivariate growth models of personality change were estimated —one for each FFM domain — in order to assess longitudinal change and self-other agreement on longitudinal change. Figure 1 displays an example bivariate growth model. The fit indices, estimated means, variances, and standard errors of the intercepts and slopes for the bivariate latent growth models are provided in Table 4. All models met subjective standards for good fit (e.g., RMSEA and SRMR <.08 and CFI > .90; Kline, 2015), with the exception of extraversion, which met good fit according to RMSEA $=.059(90 \% \mathrm{CI}=.058, .061)$, but not quite by CFI (.899) or SRMR (.099). 
Intercept means and variances were significant in each of the five models. Slope variances were also significant in each model, indicating that both the self and informants reported targets as changing in different ways across time. Self-reports indicated significant decreases in extraversion and openness across time, and no significant changes in neuroticism, agreeableness, or conscientiousness. Informant-reports indicated significant decreases in extraversion, agreeableness, and conscientiousness, and no significant changes in neuroticism or openness across time ${ }^{2}$.

Self-other agreement on longitudinal change was estimated by examining the convergence between the latent self- and informant-slopes (presented in Table 5). The self-slopes and informant-slopes covaried significantly—and at large effect sizes (e.g., > .50; Cohen, 1992) — in all FFM domains. This indicates strong self-other agreement on latent personality change across time. Lower self-report slope values (i.e., more decline or less growth) were associated with lower informant-report slope values, and vice versa. Self-other agreement on initial status was estimated by examining the convergence between the latent self- and informant-intercepts (Table 5). The self- and informant-intercepts were also significantly associated in each model — and at large effect sizes — indicating that self- and informant-reports also showed agreement on initial status within each FFM domain. Higher self-reports of each domain were associated with higher informant-reports of each domain, and vice versa. In sum, people agreed highly on target initial status and personality change.

There were several small, but statistically significant, negative slope-intercept covariances within the informant-perspective, but there were no significant slope-intercept

\footnotetext{
${ }^{2}$ Ten univariate models (i.e., five self-report models and five informant-report models_-one for each FFM domain) were estimated to compare latent slope and intercept means with the five bivariate models. The results were nearly identical and are presented in Tables S2 and S3 of the supplemental materials.
} 
covariances within the self-report perspective (Table 5). Positive associations mean the higher the intercept, the higher the slope value and negative associations mean the lower the intercept, the higher the slope value (Burant 2016; Duncan \& Duncan, 2004). The slopes and intercepts within informant-reports covaried significantly (and negatively) in neuroticism, extraversion, and openness, indicating that the lower the informant-reported intercept, the higher the informantreported slope values across the study. The size of these effects was small (Table 5). The slopes and intercepts did not significantly covary within self-reports in any FFM domain. Across perspectives, the self-report extraversion intercept and informant-report extraversion slope covaried significantly, indicating that the lower the self-reported initial status in extraversion, the higher the slope value reported by the informants across the study.

The influence of covariates on longitudinal agreement on personality change was examined by adding covariates to each of the five bivariate latent growth models. The variables of age, partner status (i.e., romantic partner/not romantic partner), length of acquaintance, late second wave completion (yes/no), and change in informant across the study (yes/no), were added as predictors of the latent intercepts and slopes. The addition of the covariates into the models did not change the patterns of significance in self-other associations presented in Table 5, with the exception that the association between the extraversion self-intercept and the extraversion informant slope was no longer statistically significant. The results of the models are presented in Tables S5-S9 of the supplemental materials.

\section{Convergence Between Longitudinal and Retrospective Change}

The convergence between longitudinal and retrospective change was estimated by examining associations between the latent self- and informant-slopes and latent retrospectivereport variables. Five additional bivariate models were estimated including the retrospective 
change variables - one for each FFM domain. An example model is presented in Figure 2. Direct paths were specified from latent self and informant retrospective-change variables to the latent slopes (i.e., longitudinal change). Direct paths were also specified from the latent retrospective variables to the intercepts to examine the relationship between retrospective change and initial status $^{3}$. For consistency, only the 30 NEO-PI-R items corresponding to the 30 retrospective change items were used to measure longitudinal change.

Results of these models are presented in Table 6. Within self-reports, associations between retrospective change and longitudinal change factors were statistically significant in the domains of neuroticism, extraversion, openness, and conscientiousness. For example, retrospective self-reported neuroticism change was significantly associated with longitudinal self-reported neuroticism change. The effect size was moderate (Cohen, 1992; Ferguson, 2009) for neuroticism, extraversion, and conscientiousness, and unidentified for openness (due to a negative — non-significant—self-report slope variance in the openness model) ${ }^{4}$. Within informant-reports, associations between retrospective and longitudinal change factors were statistically significant in all five domains. The effect size was moderate for neuroticism, extraversion, openness, and conscientiousness, and small for agreeableness. There were no significant associations across perspectives; that is, retrospective change from one perspective did not significantly predict longitudinal change from the other perspective. The unstandardized

\footnotetext{
${ }^{3}$ All models displayed good subjective fit indices (presented in Table S10 of the supplemental materials). The conscientiousness model was not positive definite until constraints on the latent conscientiousness variable residuals were removed. This did not drastically change the original problematic model estimates, which are presented in Table S11 of the supplemental materials.

${ }^{4}$ To ensure that the standardized regression coefficient did indicate a moderate effect size, we also estimated these models with correlations between the variables instead of regressions (correlation coefficients are traditionally thought of as measures of effect size). The sizes of the correlations were similar to the sizes of the regression coefficients - supporting the moderate size of the effect — and are presented in Table S12 of the supplemental materials.
} 
regression coefficients predicting the latent growth parameters can be interpreted as in linear regression (Bollen \& Curran, 2006). For example, on the 5-point Likert-type scale used for both longitudinal and retrospective variables in the present study, a one-point decrease on the informant-reported retrospective neuroticism scale was associated with a 0.134-point decrease in longitudinal informant-reported neuroticism between each wave, and thus a 0.268-point decrease across the entire study, holding other variables constant ${ }^{5}$.

The convergence between retrospective change and initial status was also estimated by examining associations between latent retrospective change and the latent self- and informantintercepts. Within self-reports, extraversion, openness, and conscientiousness intercepts were significantly associated with retrospective change. This means that retrospective change in these domains was associated with higher initial status in these domains (see Table 6). For example, for each point higher in self-reported retrospective extraversion change, self-reports of extraversion at baseline were .665-points higher. The effect size was large for openness, moderate for extraversion, and small for conscientiousness. Within informant-reports, extraversion, openness, agreeableness, and conscientiousness intercepts were significantly associated with retrospective change in these domains - all at small effect sizes. Across perspectives, latent self-report retrospective change showed significant — and small effect sizeassociations with informant-report intercepts in extraversion, openness, agreeableness, and conscientiousness. This indicates that higher self-reported retrospective change in these domains was associated with higher initial status of these domains from the informant-perspective (and lower levels in the case of agreeableness, for which the association was negative).

\footnotetext{
${ }^{5}$ Results of models using the full NEO-PI-R to measure longitudinal change also indicated significant, although reduced, convergence and are presented in Table S13 the supplemental materials. Results of models predicting only the slope indicated similar-sized estimates.
} 
Models including the age, gender, partner status, length of acquaintance, late second wave, and new informant covariates were estimated and demonstrated that association estimates were similar in size. Association estimates of the slopes were again significant in all self-report models except for agreeableness, and informant-reported retrospective change estimates predicting informant-reported slopes were again significant in all domains. There were some small differences in some of these associations after the inclusion of covariates, however, and results of these models (including fit indices and coefficients) are presented in Tables S14-S18 of the supplemental materials.

\section{Discussion}

Longitudinal research designs are required to examine the convergence between self and informant-reports of longitudinal and retrospective personality change, yet few longitudinal studies include informant-reports or retrospective reports. Longitudinal studies have found littleto-no convergence between self-and informant reports of longitudinal personality change (McCrae, 1993; Watson \& Humrichouse, 2006). Likewise, studies have found modest levels of convergence between longitudinal and retrospective reports of change in all FFM domains (Herbst et al., 2000; Robins et al., 2005), and have not examined retrospective change from the informant-report. Authors have concluded that there is "little convergence between [self-and informant-report longitudinal] change assessments" (Watson \& Humrichouse, 2006, p. 972) and that retrospective "judgements of personality change are discordant more often than not" (Herbst et al., 2000). However, prior longitudinal studies of retrospective change have been limited by sole reliance on self-reports, one-item assessments of retrospective change, and data from only two time points, and have not yet taken advantage of statistical methods designed to assess change using latent variables. Prior studies of self--other agreement on longitudinal change have 
also been few in number, limited by relatively smaller sample sizes, and reliance on two time points. The uniqueness, reliability, and accuracy of change measurement in the present study was improved by the use of informant-reports, multi-item assessments of change, a large representative sample, and latent growth modeling across three time points.

We found large effects for self-other agreement on longitudinal personality change in all FFM domains. These findings differ from prior studies of self-other agreement on longitudinal personality change that reported little convergence between personality change variables from self- and informant-reports across time. The present findings indicate that self-other agreement on personality change may in fact be larger than what has been demonstrated previously. Prior null findings may have been limited by smaller samples and unique relationships between target participants and their informants (e.g. newlyweds). In contrast to what is usually found regarding self-other agreement on neuroticism, we found that self-other agreement on longitudinal change in neuroticism was the highest out of all FFM domains. This result would, in fact, align with the findings of McCrae (1993) and Watson and Humrichouse (2006), who found relatively higher (although still modest effect size) self-other agreement on neuroticism change. In light of the prior findings of relatively lower self-other agreement on neuroticism, this finding would also support the idea that changes in neuroticism might be particularly noticeable (and therefore more agreed upon by the self and others). Personality changes in all domains were agreed upon at large effect sizes by the self and informants, however. In sum, the present findings indicate that people do actually agree on longitudinal personality change in all FFM domains, in addition to agreeing cross-sectionally. However, these findings should be interpreted in the context of the present sample (i.e. older adulthood), in which there was a relatively long length of acquaintance between targets and informants (the mean was approximately 30 years). 
Results from the present study also indicate that retrospective reports of personality change converge with longitudinal change — specifically, self-reports in neuroticism, extraversion, openness, and conscientiousness, and informant-reports in all FFM domains. The moderate effect sizes of the convergence exceeded expectations based on what had been shown previously in the literature and based on our replication of analyses used previously in the literature. Most importantly, informant retrospective-reports performed at least as well as selfreports, and low self-other agreement correlations on retrospective-reports in all FFM domains indicated that informants were providing information that was mostly unique from self-reports. This unique information appears valid; these results suggest that people are able to report accurately on their personality change in older adulthood and that informants are also able to report accurately on personality change that they have described in targets in later life. The unique information gathered from informant-reports may be particularly useful. For example, it may offer unique predictive value for important life outcomes. Indeed, informant-reports of personality change have been useful for identifying cognitive decline (Balsis et al., 2005; Benedict et al., 2001; Chatterjee et al., 1992; Duchek et al., 2007). In sum, we conclude that there may be greater convergence between longitudinal and retrospective-reports of personality change than has been reported previously.

The present results are useful for validating the measurement of personality change across time. The expansive literature on personality development relies on the assumption that measuring personality change via changes in questionnaire responses across time are valid measurements of personality change. Convergence between longitudinal and retrospective change from both perspectives has not often been examined and has been limited by a variety of 
methodological issues. Results of the present study provide constructive and rare validation evidence regarding the longitudinal measurement of personality change.

The present findings also contribute to the literature by providing data on mean-level change in older adulthood. Our findings support the "end of maturity" hypothesis, in that participants were decreasing in extraversion and openness according to self-reports and decreasing in extraversion, agreeableness, and conscientiousness according to informant-reports. There was agreement across sources regarding extraversion; both the self and others saw declines in extraversion in older adulthood. Prior studies have demonstrated informant-reported declines in extraversion (Costa \& McCrae, 1988; Watson \& Humrichouse, 2006). Our study adds that informant-reports also indicate declines in extraversion specifically in older adulthood. However, the present findings also indicate self-other discrepancies: At this stage in life, selfreports noted a decrease in openness, while informants did not, and informant-reports noted decreases in agreeableness and conscientiousness, while self-reports did not. The present findings support previous suggestions that new trends in personality change begin in older adulthood, an effect that has been called the end of maturity (Lucas \& Donnellan, 2011). These patterns may then set the stage for continued personality change into later life. It is possible that with continued personality changes on the horizon, both the self and others notice a decline in extraversion, but related changes in openness are first noticed more prominently by the self, while changes in agreeableness and conscientiousness are more easily recognized by others.

Older adults and their informants in the present study reported less personality change than has been documented previously among college students and middle-aged adults. This result naturally extends the findings of retrospective-reported change across the lifespan and adds that informants of older adults also perceive less change. People seem to perceive less 
retrospective personality change as they age. Older adults also retrospectively reported almost as much negative change as positive change. Informants, who were close to target participants, did not seem to provide a more positive account of personality change. Although there was less retrospective change reported, these reports could have important implications for health and well-being. It will be important in future analyses of data from this project and similar investigations to examine variables that are differentially related to positive and negative changes in personality traits during later life as well as the impact of these changes on related outcomes including health and mortality.

Our results dovetail with those of Herbst et al. (2000), who found that people higher in openness reported more global change. Our findings indicate that, in particular, being more extraverted, open, and conscientious is positively associated with reporting change specifically in those domains. The effect size for openness was large: Targets who self-reported more openness change were more open. The effect size was moderate for extraversion and small for conscientiousness. From the informant-perspective, these effects were also significant, but had small effect sizes. This means that targets' reports of retrospective change are perhaps more influenced by their actual levels of the FFM personality traits than are informant-reports. We also found cross-method effects where retrospective self-reports of extraversion, openness, agreeableness, and conscientiousness were associated with informant-reported initial status in those domains. These effects were small and are complicated to interpret, but they may implyfor example in extraversion - that the higher the self-report of retrospective extraversion change, the higher the informant-report extraversion initial status and vice versa: The lower the selfreport of retrospective extraversion change, the lower the informant-report extraversion initial status. While self-reports of retrospective change were related to informant-reports of initial 
levels of the FFM, the reverse was not true (i.e., informant-reports of retrospective change were not significantly related to self-reports of initial levels of the FFM). Future research using multimethod assessment will continue to clarify these findings.

These findings indicate that individual differences in the FFM are related to retrospective change reports. Other factors related to older adulthood, such as characteristic life events (Bleidorn, Hopwood, \& Lucas, 2016), health (Jackson et al., 2017), and time perception (Carstensen, Isaacowitz, \& Charles, 1999) may influence how retrospective personality change is reported. Participants in the present study were at a stage in life that is frequently associated with retirement, becoming grandparents, loss of partners, and for some the onset of new challenges such as health-related problems. Future research examining the effects of both positive and negative life events, as well as time perception, on personality change will help be helpful for clarifying further the convergence of longitudinal and retrospective reports of change.

It should be noted also that informants in the present study had known the target participants for many years, on average. Therefore, while the reliability and robustness of informant accounts of change appear to be useful for close-other informants, these findings might not translate to informants who do not know participants as well, or to informants who have not known target participants long. Our results do indicate, however, that even informants who are very close to the targets provide different information that is potentially important and not limited to positive aspects of personality change.

\section{Limitations}

The present analyses do have several limitations. For one, the self-rated agreeableness NEO-PI-R items in the retrospective change models were less reliable at the longitudinal assessment waves. Self-rated agreeableness was also the one estimate of retrospective change 
that did not significantly converge with longitudinal change. It is possible that the null findings in self-reported agreeableness stem from its lower reliability of measurement across time, rather than a true lack of convergence. For this reason, the results regarding agreeableness should be interpreted with caution.

The present findings are limited by the relatively smaller amount of retrospectivelyreported change (compared to that observed among younger participants). While the smaller amount of change may be a limitation, it is not a reason to neglect the examination of change, as the research literature has been clear about the important outcomes that are associated with personality change in this age group (e.g., dementia and mortality). Of course, future studies will benefit from collecting data on change with more frequent assessment points.

\section{Conclusions}

Surprisingly, longitudinal research examining the validity of personality change judgments is sparse, even though personality change importantly predicts mortality (Mroczek \& Spiro, 2007), substance abuse (Turiano et al., 2012), mental and physical health problems (Magee et al., 2013; Takahashi et al., 2013), metabolic syndrome (Human et al., 2013), and precedes dementia (Balsis et al., 2005; Chatterjee et al., 1992). The present study was novel in employing both self- and informant-reports of retrospective and longitudinal personality change, using a longer and thus more reliable measure of retrospective change, and using latent growth modeling techniques across three time points to investigate the convergence of retrospective and longitudinal reports and self-other agreement on longitudinal personality change. Findings differ from what has been found previously; self-other agreement on longitudinal change was strong and retrospective and longitudinal reports of change converged at moderate effect sizes. The present results indicate that both self- and informant-retrospective reports of personality change 
converge with longitudinal change, with informant-reports converging as highly as self-reports, despite being largely unique from self-reports. Although hundreds of studies have been conducted on personality development, the present findings are rare in that they provide validation evidence to the longitudinal assessment of personality change. The present results also provide validation evidence for retrospective assessments of personality change and indicate that informant-reports may offer an important alternative tool for gathering a unique and nuanced assessment of change in personality assessment batteries. 


\section{References}

Balsis, S., Carpenter, B. D., \& Storandt, M. (2005). Personality change precedes clinical diagnosis of dementia of the Alzheimer type. The Journals of Gerontology: Series B, 60, 98-101.

Balsis, S., Cooper, L. D., \& Oltmanns, T. F. (2015). Are informant reports of personality more internally consistent than self reports of personality? Assessment, 22, 399-404.

Benedict, R. H., Priore, R. L., Miller, C., Munschauer, F., \& Jacobs, L. (2001). Personality disorder in multiple sclerosis correlates with cognitive impairment. The Journal of Neuropsychiatry and Clinical Neurosciences, 13, 70-76.

Bleidorn, W., Hopwood, C. J., \& Lucas, R. E. (2018). Life events and personality trait change. Journal of Personality, 86, 83-96.

Bollen, K. A., \& Curran, P. J. (2006). Latent curve models: A structural equation perspective. Hoboken, NJ: Wiley.

Burant, C. J. (2016). Latent growth curve models: tracking changes over time. The International Journal of Aging and Human Development, 82, 336-350.

Carstensen, L. L., Isaacowitz, D. M., \& Charles, S. T. (1999). Taking time seriously: A theory of socioemotional selectivity. American Psychologist, 54, 165-181.

Chatterjee, A., Strauss, M. E., Smyth, K. A., \& Whitehouse, P. J. (1992). Personality changes in Alzheimer's disease. Archives of Neurology, 49, 486-491.

Chen, F. F. (2007). Sensitivity of goodness of fit indexes to lack of measurement invariance. Structural Equation Modeling, 14, 464-504. 
Clifton, A., Turkheimer, E., \& Oltmanns, T. F. (2005). Self- and peer perspectives on pathological personality traits and interpersonal problems, Psychological Assessment, 17, $123-131$.

Cohen, J. (1992). A power primer. Psychological Bulletin, 112, 155-159.

Connelly, B. S., \& Ones, D. S. (2010). An other perspective on personality: Meta-analytic integration of observers' accuracy and predictive validity. Psychological Bulletin, 136, 1092.

Conway, M., \& Ross, M. (1984). Getting what you want by revising what you had. Journal of Personality and Social Psychology, 47, 738-748.

Costa, P. T., \& McCrae, R. R. (1992). Revised NEO Personality Inventory (NEO PI-R) and NEO Five-Factor Inventory (NEO-FFI) professional manual. Odessa, FL: Psychological Assessment Resources.

Costa, P. T., \& McCrae, R. R. (1988). Personality in adulthood: A six-year longitudinal study of self-reports and spouse ratings on the NEO Personality Inventory. Journal of Personality and Social Psychology, 54, 853.

Curran, P. J., Bauer, D. J., \& Willoughby, M. T. (2004). Testing main effects and interactions in latent curve analysis. Psychological Methods, 9, 220.

Duchek, J. M., Balota, D. A., Storandt, M., \& Larsen, R. (2007). The power of personality in discriminating between healthy aging and early-stage Alzheimer's disease. The Journals of Gerontology Series B: Psychological Sciences and Social Sciences, 62, 353-361.

Duncan, T. E., \& Duncan, S. C. (2004). An introduction to latent growth curve modeling. Behavior Therapy, 35, 333-363. 
Ferguson, C. J. (2009). An effect size primer: A guide for clinicians and researchers. Professional Psychology: Research and Practice, 40, 532-538.

Fiedler, E. R., Oltmanns, T. F., \& Turkheimer, E. (2004). Traits associated with personality disorders and adjustment to military life: Predictive validity of self and peer reports. Military Medicine, 169, 207-211.

Funder, D. C. (1995). On the accuracy of personality judgment: A realistic approach. Psychological Review, 102, 652 -670.

Furr, R. M., \& Bacharach, V. R. (2008). Psychometrics: An introduction. Thousand Oaks, CA: Sage Publications.

Fleeson, W., \& Heckhausen, J. (1997). More or less "me” in past, present, and future: Perceived lifetime personality during adulthood. Psychology and Aging, 12, 125-136.

Göllner, R., Roberts, B. W., Damian, R. I., Lüdtke, O., Jonkmann, K., \& Trautwein, U. (2017). Whose "storm and stress" is it? Parent and child reports of personality development in the transition to early adolescence. Journal of Personality, 85, 376-387.

Handel, A., Kimhi, S., \& Leviatan, U. (1983). Perceived retrospective change of self among the middle-aged in the middle-aged in the kibbutz. International Journal of Behavioral Development, 6, 241-260.

Haynes, S. N., Smith, G. T., \& Hunsley, J. D. (2011). Scientific foundations of clinical assessment. New York: Routledge.

Herbst, J. H., McCrae, R. R., Costa, P. T., Feaganes, J. R., \& Siegler, I. C. (2000). Selfperceptions of stability and change in personality at midlife: The UNC alumni heart study. Assessment, 7, 379-388. 
Human, L. J., Biesanz, J. C., Miller, G. E., Chen, E., Lachman, M. E., \& Seeman, T. E. (2013). Is change bad? Personality change is associated with poorer psychological health and greater metabolic syndrome in midlife. Journal of Personality, 81, 249-260.

Jackson, J. J. \& Allemand, M. (2014). Moving personality development research forward: utilizing structural equation models. European Journal of Personality, 28, 300-310.

Jackson, J. J., Connolly, J. J., Garrison, S. M., Leveille, M. M., \& Connolly, S. L. (2015). Your friends know how long you will live: A 75-year study of peer-rated personality traits. Psychological Science, 26, 335-340.

Jackson, J.J., Weston, S. J. \& Schultz, L. (2017). Health and personality development. (Ed. Jule Specht), Handbook of Personality Development.

John, O. P., \& Robins, R. W. (1994). Accuracy and bias in self-perception: individual differences in self-enhancement and the role of narcissism. Journal of Personality and Social Psychology, 66, 206-219.

John, O. P., \& Robins, R. W. (1993). Determinants of interjudge agreement on personality traits: The Big Five domains, observability, evaluativeness, and the unique perspective of the self. Journal of Personality, 61, 521-551.

Kline, R. B. (2015). Principles and practice of structural equation modeling. New York, NY: Guilford Press.

Kolar, D. W., Funder, D. C., \& Colvin, C. R. (1996). Comparing the accuracy of personality judgments by the self and knowledgeable others. Journal of Personality, 64, 311-337.

Levine, L. J., \& Safer, M. A. (2002). Sources of bias in memory for emotions. Current Directions in Psychological Science, 11, 169-173. 
Luan, Z., Hutteman, R., Denissen, J. J., Asendorpf, J. B., \& van Aken, M. A. (2017). Do you see my growth? Two longitudinal studies on personality development from childhood to young adulthood from multiple perspectives. Journal of Research in Personality, 67, 4460.

Lucas, R. E., \& Donnellan, M. B. (2011). Personality development across the life span: Longitudinal analyses with a national sample from Germany. Journal of Personality and Social Psychology, 101, 847-861.

Lüdtke, O., Roberts, B. W., Trautwein, U., \& Nagy, G. (2011). A random walk down university avenue: life paths, life events, and personality trait change at the transition to university life. Journal of Personality and Social Psychology, 101, 620-637.

Magee, C. A., Heaven, P. C., \& Miller, L. M. (2013). Personality change predicts self-reported mental and physical health. Journal of Personality, 81, 324-334.

McCrae, R. R. (1993). Moderated analyses of longitudinal personality stability. Journal of Personality and Social Psychology, 65, 577-585.

McCrae, R. R., \& Costa, P. T. (1987). Validation of the five-factor model of personality across instruments and observers. Journal of Personality and Social Psychology, 52, 81-90.

Mroczek, D. K., \& Spiro, A. (2007). Personality change influences mortality in older men. Psychological Science, 18, 371-376.

Muthén, B. O. (2013, August 21). Variances of growth factors [Msg 44]. Message posted to http://www.statmodel.com/discussion/messages/14/228.html?1395703447

Newsom, J. T. (2015). Longitudinal structural equation modeling: A comprehensive introduction. Routledge. 
Norman, W. T. (1963). Toward an adequate taxonomy of personality attributes: Replicated factor structure in peer nomination personality ratings. The Journal of Abnormal and Social Psychology, 66, 574-583.

Oltmanns, T. F., Rodrigues, M. M., Weinstein, Y., \& Gleason, M. E. (2014). Prevalence of personality disorders at midlife in a community sample: Disorders and symptoms reflected in interview, self, and informant reports. Journal of Psychopathology and Behavioral Assessment, 36, 177-188.

Oltmanns, T. F., \& Turkheimer, E. (2006). Perceptions of self and others regarding pathological personality traits. In R. F. Krueger \& J. L. Tackett (Eds.), Personality and psychopathology (pp. 71-111). New York: Guilford.

Quoidbach, J., Gilbert, D. T., \& Wilson, T. D. (2013). The end of history illusion. Science, 339, 96-98.

R Core Team. (2013). R: A language and environment for statistical computing. Vienna, Austria: R Foundation for Statistical Computing.

Raudenbush, S. W., \& Bryk, A. S. (2002). Hierarchical linear models: Applications and data analysis methods (Vol. 1). Sage.

Roberts, B. W., \& DelVecchio, W. F. (2000). The rank-order consistency of personality traits from childhood to old age: A quantitative review of longitudinal studies. Psychological Bulletin, 126, 3-25.

Roberts, B. W., Walton, K. E., \& Viechtbauer, W. (2006). Patterns of mean-level change in personality traits across the life course: A meta-analysis of longitudinal studies. Psychological Bulletin, 132, 1. 
Roberts, B. W., Wood, D., \& Caspi, A. (2008). The development of personality traits in adulthood. Handbook of personality: Theory and research, 3, 375-398.

Robins, R. W., Noftle, E. E., \& Trzesniewski, K. H. (2005). Do people know how their personality has changed? Correlates of perceived and actual personality change in young adulthood. Journal of Personality, 73, 489-521.

Rocke, C., Hoppmann, C. A., \& Klumb, P. L. (2011). Correspondence between retrospective an dmomentary ratings of positive and negative affect in old age: Findings from a one-year measurement burst design. The Journals of Gerontology: Series B, 66, 411-415.

Rogosa, D., Brandt, D., \& Zimowski, M. (1982). A growth curve approach to the measurement of change. Psychological Bulletin, 92, 726-748.

Rohrer, J. M., Egloff, B., Kosinski, M., Stillwell, D., \& Schmukle, S. C. (2018). In your eyes only? Discrepancies and agreement between self- and other-reports of personality from age 14 to 29. Journal of Personality and Social Psychology, 115, 304-320.

Ross, M., \& Wilson, A. E. (2003). Autobiographical memory and conceptions of self: Getting better all the time. Current Directions in Psychological Science, 12, 66-69.

Rosseel, Y. (2012). lavaan: An R Package for structural equation modeling. Journal of Statistical Software, 48, 1-36. http://www.jstatsoft.org/v48/i02/

Ryff, C. D. (1982). Self-perceived personality change in adulthood and aging. Journal of Personality and Social Psychology, 42, 108-115.

Siegler, I. C., Costa, P. T., Brummett, B. H., Helms, M. J., Barefoot, J. C., Williams, R. B., ... \& Day, R. S. (2003). Patterns of change in hostility from college to midlife in the UNC Alumni Heart Study predict high-risk status. Psychosomatic Medicine, 65, 738-745. Silka, L. (1989). Intuitive judgments of change. New York, NY: Springer-Verlag. 
Specht, J., Egloff, B., \& Schmukle, S. C. (2011). Stability and change of personality across the life course: The impact of age and major life events on mean-level and rank-order stability of the Big Five. Journal of Personality and Social Psychology, 101, 862.

Stark, S., Chernyshenko, O. S., \& Drasgow, F. (2006). Detecting differential item functioning with confirmatory factor analysis and item response theory: Toward a unified strategy. Journal of Applied Psychology, 91, 1292.

Takahashi, Y., Edmonds, G., Jackson, J. J. Roberts, B.W. (2013). Longitudinal correlated changes in conscientiousness, preventative health-related behaviors, and physical health. Journal of Personality. 81, 417-427. DOI: 10.1111/jopy.12007

Turiano, N. A., Pitzer, L., Armour, C., Karlamangla, A., Ryff, C. D., \& Mroczek, D. K. (2011). Personality trait level and change as predictors of health outcomes: Findings from a national study of Americans (MIDUS). Journals of Gerontology Series B: Psychological Sciences and Social Sciences, 67, 4-12.

Turiano, N. A., Whiteman, S. D., Hampson, S. E., Roberts, B. W., \& Mroczek, D. K. (2012). Personality and substance use in midlife: Conscientiousness as a moderator and the effects of trait change. Journal of Research in Personality, 46, 295-305.

Vazire, S. (2010). Who knows what about a person? The self-other knowledge asymmetry (SOKA) model. Journal of Personality and Social Psychology, 98, 281-300.

Watson, D., \& Humrichouse, J. (2006). Personality development in emerging adulthood: Integrating evidence from self-ratings and spouse ratings. Journal of Personality and Social Psychology, 91, 959.

Wilson, A. E., \& Ross, M. (2001). From chump to champ: People's appraisals of their earlier and present selves. Journal of Personality and Social Psychology, 4, 572-584. 
Woodruff, D. S., \& Birren, J. E. (1972). Age changes and cohort differences in personality. Developmental Psychology, 6, 252-259. 
Table 1

Retrospective Personality Change Statistics

\begin{tabular}{lccccccccc}
\hline & FFM & \multicolumn{3}{c}{ Stayed } & & & & & \\
& Domain & Decreased & the same & Increased & $M$ & $S D$ & Skewness & Kurtosis & $\alpha$ \\
\hline Self & $\mathrm{N}$ & 15 & 73 & 11 & 1.76 & 0.57 & -0.65 & 1.12 & .82 \\
& $\mathrm{E}$ & 15 & 71 & 14 & 2.05 & 0.38 & 0.23 & 2.36 & .57 \\
& $\mathrm{O}$ & 10 & 76 & 14 & 2.22 & 0.46 & 0.73 & 2.06 & .68 \\
& $\mathrm{~A}$ & 4 & 81 & 15 & 2.24 & 0.36 & 1.53 & 2.75 & .64 \\
\hline Informant & $\mathrm{C}$ & 7 & 80 & 13 & 2.07 & 0.42 & 0.70 & 3.92 & .77 \\
& $\mathrm{~N}$ & 14 & 72 & 14 & 1.99 & 0.50 & -0.49 & 2.89 & .81 \\
& $\mathrm{E}$ & 11 & 75 & 14 & 1.97 & 0.35 & 0.06 & 4.13 & .65 \\
& $\mathrm{O}$ & 6 & 86 & 9 & 2.03 & 0.32 & 0.13 & 10.21 & .66 \\
& $\mathrm{~A}$ & 6 & 84 & 11 & 2.09 & 0.33 & 0.78 & 8.22 & .70 \\
\hline
\end{tabular}

Note. $\mathrm{s}=\operatorname{self}(n=1,100), \mathrm{i}=$ informant $(n=891) . \mathrm{E}=$ extraversion, $\mathrm{A}=$ agreeableness,

$\mathrm{C}=$ conscientiousness, $\mathrm{N}=$ neuroticism, $\mathrm{O}=$ openness. $\%$ increased and decreased were calculated

as $1 S D$ greater than or $1 S D$ less than the mean. 
Table 2

Longitudinal NEO-PI-R Personality Statistics

NEO Items Corresponding with Full NEO-PI-R Scales Retrospective Items

\begin{tabular}{|c|c|c|c|c|c|c|c|c|}
\hline & $\begin{array}{c}\text { FFM } \\
\text { Domain }\end{array}$ & & Wave 1 & Wave 2 & Wave 3 & Wave 1 & Wave 2 & Wave 3 \\
\hline \multirow[t]{15}{*}{ Self } & \multirow[t]{3}{*}{$\mathrm{N}$} & $M$ & 1.51 & 1.44 & 1.50 & 1.44 & 1.37 & 1.45 \\
\hline & & $S D$ & .43 & .43 & .45 & .65 & .65 & .66 \\
\hline & & $\alpha$ & .92 & .93 & .93 & .71 & .72 & .74 \\
\hline & \multirow[t]{3}{*}{$\mathrm{E}$} & $M$ & 2.25 & 2.24 & 2.22 & 2.42 & 2.40 & 2.38 \\
\hline & & $S D$ & .38 & .39 & .40 & .55 & .55 & .57 \\
\hline & & $\alpha$ & .88 & .90 & .90 & .66 & .70 & .72 \\
\hline & \multirow[t]{3}{*}{$\mathrm{O}$} & $M$ & 2.34 & 2.33 & 2.35 & 2.50 & 2.47 & 2.47 \\
\hline & & $S D$ & .38 & .39 & .39 & .70 & .69 & .72 \\
\hline & & $\alpha$ & .89 & .90 & .90 & .69 & .72 & .74 \\
\hline & \multirow[t]{3}{*}{ A } & $M$ & 2.70 & 2.73 & 2.70 & 2.96 & 2.99 & 2.95 \\
\hline & & $S D$ & .32 & .30 & .32 & .46 & .43 & .46 \\
\hline & & $\alpha$ & .86 & .86 & .88 & .50 & .49 & .54 \\
\hline & \multirow[t]{3}{*}{$\mathrm{C}$} & $M$ & 2.57 & 2.60 & 2.59 & 2.79 & 2.81 & 2.81 \\
\hline & & $S D$ & .36 & .36 & .38 & .50 & .50 & .53 \\
\hline & & $\alpha$ & .89 & .90 & .91 & .64 & .68 & .72 \\
\hline \multirow[t]{15}{*}{ Informant } & \multirow[t]{3}{*}{$\mathrm{N}$} & $M$ & 1.62 & 1.62 & 1.58 & 1.79 & 1.75 & 1.69 \\
\hline & & $S D$ & .55 & .54 & .55 & .80 & .77 & .77 \\
\hline & & $\alpha$ & .94 & .95 & .95 & .78 & .81 & .81 \\
\hline & \multirow[t]{3}{*}{$\mathrm{E}$} & $M$ & 2.30 & 2.25 & 2.25 & 2.45 & 2.38 & 2.36 \\
\hline & & $S D$ & .45 & .43 & .46 & .64 & .62 & .64 \\
\hline & & $\alpha$ & .90 & .91 & .91 & .70 & .73 & .73 \\
\hline & \multirow[t]{3}{*}{$\mathrm{O}$} & $M$ & 2.21 & 2.22 & 2.22 & 2.38 & 2.41 & 2.38 \\
\hline & & $S D$ & .40 & .40 & .41 & .74 & .73 & .76 \\
\hline & & $\alpha$ & .89 & .90 & .90 & .70 & .75 & .77 \\
\hline & \multirow[t]{3}{*}{ A } & $M$ & 2.59 & 2.57 & 2.60 & 2.83 & 2.78 & 2.85 \\
\hline & & $S D$ & .48 & .49 & .50 & .66 & .65 & .67 \\
\hline & & $\alpha$ & .93 & .94 & .94 & .70 & .75 & .77 \\
\hline & \multirow[t]{3}{*}{$\mathrm{C}$} & $M$ & 2.67 & 2.63 & 2.63 & 2.86 & 2.82 & 2.85 \\
\hline & & $S D$ & .53 & .53 & .51 & .69 & .68 & .69 \\
\hline & & $\alpha$ & .94 & .95 & .95 & .76 & .81 & .82 \\
\hline
\end{tabular}

Note. $\mathrm{S}=$ self, $\mathrm{I}=$ informant, $\mathrm{N}=$ neuroticism, $\mathrm{E}=$ extraversion, $\mathrm{O}=$ openness, $\mathrm{A}=$ agreeableness, $\mathrm{C}=$ conscientiousness. 
Table 3

Correlations Between Observed Retrospective Change and Residual Wave 1 to Wave 3 Change Scores

\begin{tabular}{ccccc}
\hline \multirow{5}{*}{ Self } & FFM & & & $\begin{array}{c}\text { Bootstrap } \\
\text { Domain }\end{array}$ \\
& $\mathrm{N}$ & $.22 *$ & .04 & {$[.15, .29]$} \\
& $\mathrm{E}$ & $.22 *$ & .03 & {$[.15, .29]$} \\
& $\mathrm{O}$ & $.23 *$ & .03 & {$[.18, .29]$} \\
& $\mathrm{A}$ & .02 & .03 & {$[-.04, .09]$} \\
& $\mathrm{C}$ & $.18 *$ & .03 & {$[.12, .25]$} \\
\hline \multirow{5}{*}{ Informant } & $\mathrm{N}$ & $.24 *$ & .04 & {$[.16, .31]$} \\
& $\mathrm{E}$ & $.19 *$ & .04 & {$[.12, .26]$} \\
& $\mathrm{O}$ & $.27 *$ & .04 & {$[.20, .35]$} \\
& $\mathrm{A}$ & $.17 *$ & .04 & {$[.09, .26]$} \\
& $\mathrm{C}$ & $.23 *$ & .05 & {$[.14, .32]$} \\
\hline
\end{tabular}

Note. $n=$ between 1,035-1,037 for self and $n=806$ for informants, $* p<.05$. $\mathrm{S}=$ self, $\mathrm{I}=$ informant. \# = change factor estimated as negative.

Bootstrapping was conducted with 1,000 samples. 
Table 4

Bivariate Full NEO-PI-R Growth Model Parameters and Fit Indices

\begin{tabular}{lcccccc}
\hline & \multicolumn{5}{c}{ Model } \\
\hline Mean $(S E)$ & & $\mathrm{N}$ & $\mathrm{E}$ & $\mathrm{O}$ & $\mathrm{A}$ & $\mathrm{C}$ \\
& $\mathrm{i}$ & $1.490(.011) *$ & $2.250(.009) *$ & $2.337(.009) *$ & $2.710(.008) *$ & $2.579(.009) *$ \\
& $\mathrm{~s}$ & $.007(.004)$ & $-.016(.003) *$ & $-.009(.003) *$ & $-.006(.003)$ & $-.003(.003)$ \\
& $\mathrm{i} 2$ & $1.630(.014) *$ & $2.296(.011) *$ & $2.213(.010) *$ & $2.586(.012) *$ & $2.655(.013) *$ \\
& $\mathrm{~s} 2$ & $-.007(.006)$ & $-.036(.005) *$ & $-.007(.004)$ & $-.014(.006) *$ & $-.033(.006) *$ \\
\hline Variance $(S E)$ & $\mathrm{i}$ & $.139(.006) *$ & $.104(.005) *$ & $.107(.005) *$ & $.063(.003) *$ & $.097(.005) *$ \\
& $\mathrm{~S}$ & $.002(.001) *$ & $.002(.001) *$ & $.002(.001) *$ & $.002(.001) *$ & $.002(.001) *$ \\
& $\mathrm{i} 2$ & $.230(.011) *$ & $.135(.007) *$ & $.106(.006) *$ & $.171(.009) *$ & $.218(.010) *$ \\
Fit indices & $\mathrm{s} 2$ & $.010(.002) *$ & $.005(.001) *$ & $.004(.001) *$ & $.008(.002) *$ & $.007(.002) *$ \\
\hline & $\mathrm{CFI}$ & .948 & .899 & .926 & .939 & .932 \\
& $\mathrm{RMSEA}$ & $.045(.043, .046)$ & $.059(.058, .061)$ & $.048(.047, .050)$ & $.043(.041, .045)$ & $.051(.049, .053)$ \\
& SRMR & .055 & .099 & .077 & .066 & .062
\end{tabular}

Note. $N=1,620 . * p<.05 . \mathrm{s}=$ latent self-report slope, $\mathrm{i}=$ latent self-report intercept, $\mathrm{s} 2=$ latent informant-report slope, i2 = latent informant-report intercept, $\sim=$ covariance. ML estimation. 
Table 5

Convergence Between Longitudinal Self- and Informant-Report Growth Factors (Full NEO-PI-R)

\begin{tabular}{|c|c|c|c|c|c|c|c|}
\hline & & $\mathrm{s} \sim \sim \mathrm{s} 2$ & $\mathrm{i} \sim \sim \mathrm{i} 2$ & $\mathrm{i} \sim \sim \mathrm{s}$ & $\mathrm{i} 2 \sim \sim \mathrm{s} 2$ & $\mathrm{~s} \sim \sim \mathrm{i} 2$ & $\mathrm{i} \sim \sim \mathrm{s} 2$ \\
\hline \multirow[t]{4}{*}{$\mathrm{N}$} & est $(S E)$ & $.004(.001)$ & $.105(.006)$ & $.002(.002)$ & $-.012(.004)$ & $-.000(.002)$ & $-.003(.002)$ \\
\hline & $95 \% C I$ & $.002, .006$ & $.092, .117$ & $-.001, .006$ & $-.019,-.005$ & $-.005, .004$ & $-.008, .001$ \\
\hline & $p$ & $<.001$ & $<.001$ & .187 & .001 & .879 & .175 \\
\hline & $r$ & .88 & .59 & .14 & -.25 & -.02 & -.09 \\
\hline \multirow[t]{4}{*}{$\mathrm{E}$} & est $(S E)$ & $.003(.001)$ & $.088(.005)$ & $-.001(.001)$ & $-.005(.002)$ & $-.001(.001)$ & $-.003(.002)$ \\
\hline & $95 \% C I$ & $.002, .004$ & $.078, .097$ & $-.003, .002$ & $-.009, .000$ & $-.004, .001$ & $-.007, .000$ \\
\hline & $p$ & $<.001$ & $<.001$ & .488 & .044 & .376 & .044 \\
\hline & $r$ & .80 & .74 & -.05 & -.17 & -.07 & -.15 \\
\hline \multirow[t]{4}{*}{$\mathrm{O}$} & est $(S E)$ & $.002(.000)$ & $.082(.004)$ & $-.001(.001)$ & $-.005(.002)$ & $-.001(.001)$ & $-.002(.002)$ \\
\hline & $95 \% C I$ & $.001, .003$ & $.074, .091$ & $-.004, .001$ & $-.008,-.001$ & $-.003, .001$ & $-.005, .001$ \\
\hline & $p$ & $<.001$ & $<.001$ & .188 & .008 & .276 & .121 \\
\hline & $r$ & .69 & .77 & -.11 & -.21 & -.09 & -.11 \\
\hline \multirow[t]{4}{*}{ A } & est $(S E)$ & $.002(.001)$ & $.054(.004)$ & $-.001(.001)$ & $-.005(.003)$ & $-.002(.002)$ & $-.002(.002)$ \\
\hline & $95 \% C I$ & $.001, .003$ & $.047, .062$ & $-.003, .001$ & $-.010, .001$ & $-.005, .001$ & $-.005, .002$ \\
\hline & $p$ & .002 & $<.001$ & .310 & .105 & .119 & .306 \\
\hline & $r$ & .53 & .52 & -.11 & -.13 & -.14 & -.08 \\
\hline \multirow[t]{4}{*}{$\mathrm{C}$} & est $(S E)$ & $.002(.001)$ & $.081(.005)$ & $.002(.001)$ & $-.005(.003)$ & $.003(.002)$ & $-.003(.002)$ \\
\hline & $95 \% C I$ & $.001, .003$ & $.071, .091$ & $-.001, .004$ & $-.011, .001$ & $-.001, .006$ & $-.007, .001$ \\
\hline & $p$ & .001 & $<.001$ & .173 & .099 & .123 & .117 \\
\hline & $r$ & .57 & .56 & .12 & -.13 & .13 & -.11 \\
\hline
\end{tabular}

Note. $N=1,620$. bold = large effect size. $\mathrm{s}=$ latent self-report slope, $\mathrm{i}=$ latent self-report intercept, $\mathrm{s} 2=$ latent informant-report slope, i2 = latent informant-report intercept. ML estimation. 
Table 6. Retrospective Change Latent Variables Predicting Longitudinal Growth Factors

\begin{tabular}{|c|c|c|c|c|c|c|c|c|c|c|c|}
\hline \multirow[b]{2}{*}{ Retro } & \multirow[b]{2}{*}{ Model } & \multirow[b]{2}{*}{$b$} & \multicolumn{3}{|c|}{ Self Slope } & \multicolumn{6}{|c|}{ Self Intercept } \\
\hline & & & $S E$ & $95 \% C I$ & $p$ & $\beta$ & $b$ & $S E$ & $p$ & $95 \% C I$ & $\beta$ \\
\hline \multirow[t]{3}{*}{ Self } & $\mathrm{N}$ & .096 & .019 & $.060, .133$ & $<.001$ & .48 & .069 & .045 & .129 & $-.020, .157$ & .07 \\
\hline & $\mathrm{O}^{\#}$ & .090 & .023 & $.045, .135$ & $<.001$ & - & .711 & .061 & $<.001$ & $.591, .831$ & .50 \\
\hline & A & .014 & .027 & $-.038, .066$ & .595 & .07 & .042 & .058 & .468 & $-.072, .156$ & .04 \\
\hline \multirow{4}{*}{ Informant } & $\mathrm{E}$ & -.028 & .032 & $-.091, .035$ & .382 & -.10 & -.078 & .083 & .344 & $-.240, .084$ & -.05 \\
\hline & $\mathrm{O}^{\#}$ & -.013 & .039 & $-.089, .062$ & .730 & - & .200 & .122 & .102 & $-.039, .440$ & .09 \\
\hline & A & -.019 & .028 & $-.074, .036$ & .499 & -.09 & .012 & .067 & .854 & $-.119, .144$ & .01 \\
\hline & $\mathrm{C}$ & .042 & .029 & $-.015, .100$ & .147 & .27 & .083 & .053 & .115 & $-.020, .186$ & .08 \\
\hline \multirow{8}{*}{ Informant } & $\mathrm{O}^{\#}$ & -.030 & .035 & $-.098, .038$ & .393 & -.10 & .415 & .069 & $<.001$ & $.279, .552$ & .29 \\
\hline & A & -.024 & .041 & $-.104, .056$ & .555 & -.05 & -.203 & .085 & .017 & $-.370,-.035$ & -.12 \\
\hline & $\mathrm{C}$ & -.043 & .028 & $-.098, .013$ & .135 & -.16 & .153 & .067 & .023 & $.021, .285$ & .11 \\
\hline & $\mathrm{N}$ & .134 & .028 & $.079, .190$ & $<.001$ & .43 & .143 & .077 & .063 & $-.008, .293$ & .10 \\
\hline & $\mathrm{E}$ & .150 & .045 & $.061, .239$ & .001 & .43 & .320 & .102 & .002 & $.121, .519$ & .17 \\
\hline & $\mathrm{O}^{\#}$ & .192 & .057 & $.081, .303$ & .001 & .43 & .489 & .122 & $<.001$ & $.250, .729$ & .23 \\
\hline & A & .138 & .054 & $.032, .243$ & .010 & .28 & .308 & .124 & .013 & $.065, .551$ & .17 \\
\hline & $\mathrm{C}$ & .131 & .035 & $.062, .200$ & $<.001$ & .47 & .387 & .086 & $<.001$ & $.218, .555$ & .25 \\
\hline
\end{tabular}




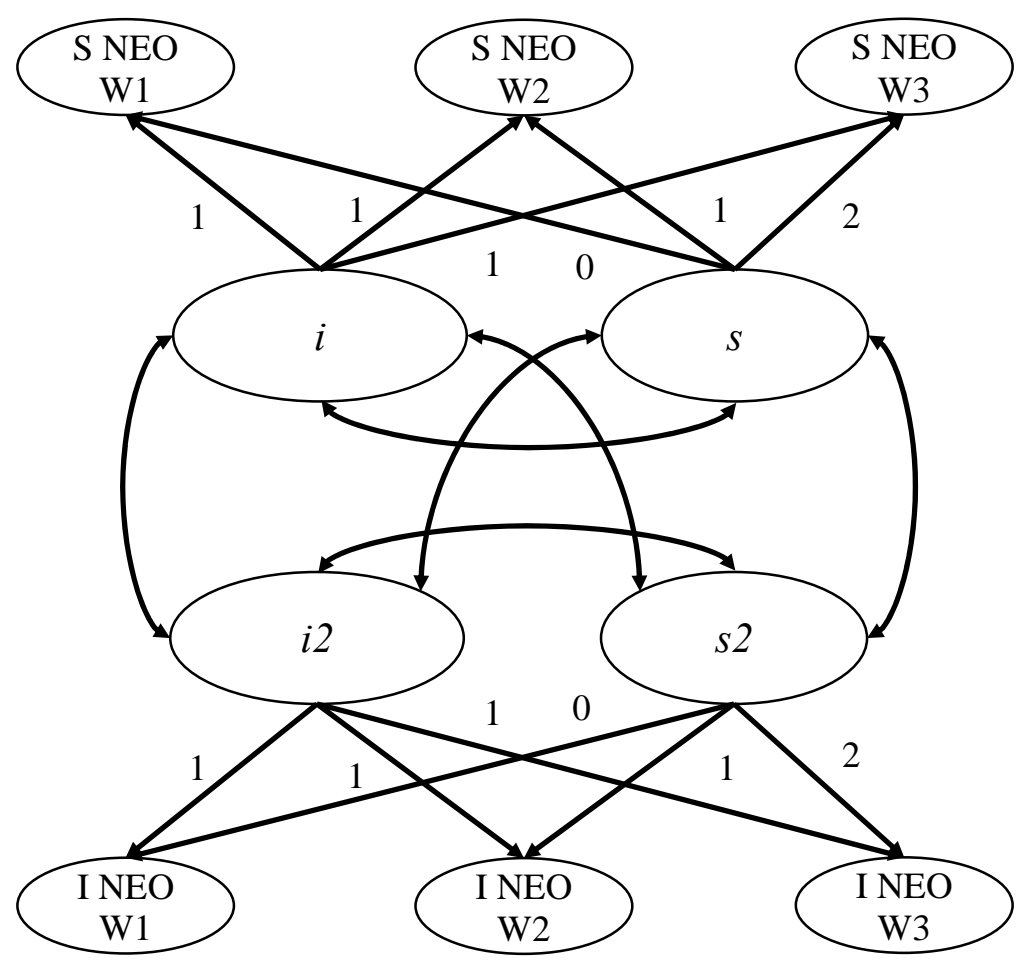

Figure 1. Bivariate latent growth model to examine self-other agreement on longitudinal personality change. $\mathrm{S}=$ self-report, $\mathrm{I}=$ informant-report, $i=$ self-report intercept, $s=$ self-report slope, $i 2$ = informant-report intercept, $s 2=$ informant-report slope. Self-other agreement is represented by the double-headed arrow from $s$ (latent self-reported personality change) to $s 2$ (latent informant-reported personality change). In each model, the six NEO-PI-R facet scores from each wave loaded individually onto each respective latent NEO-PI-R factor. 


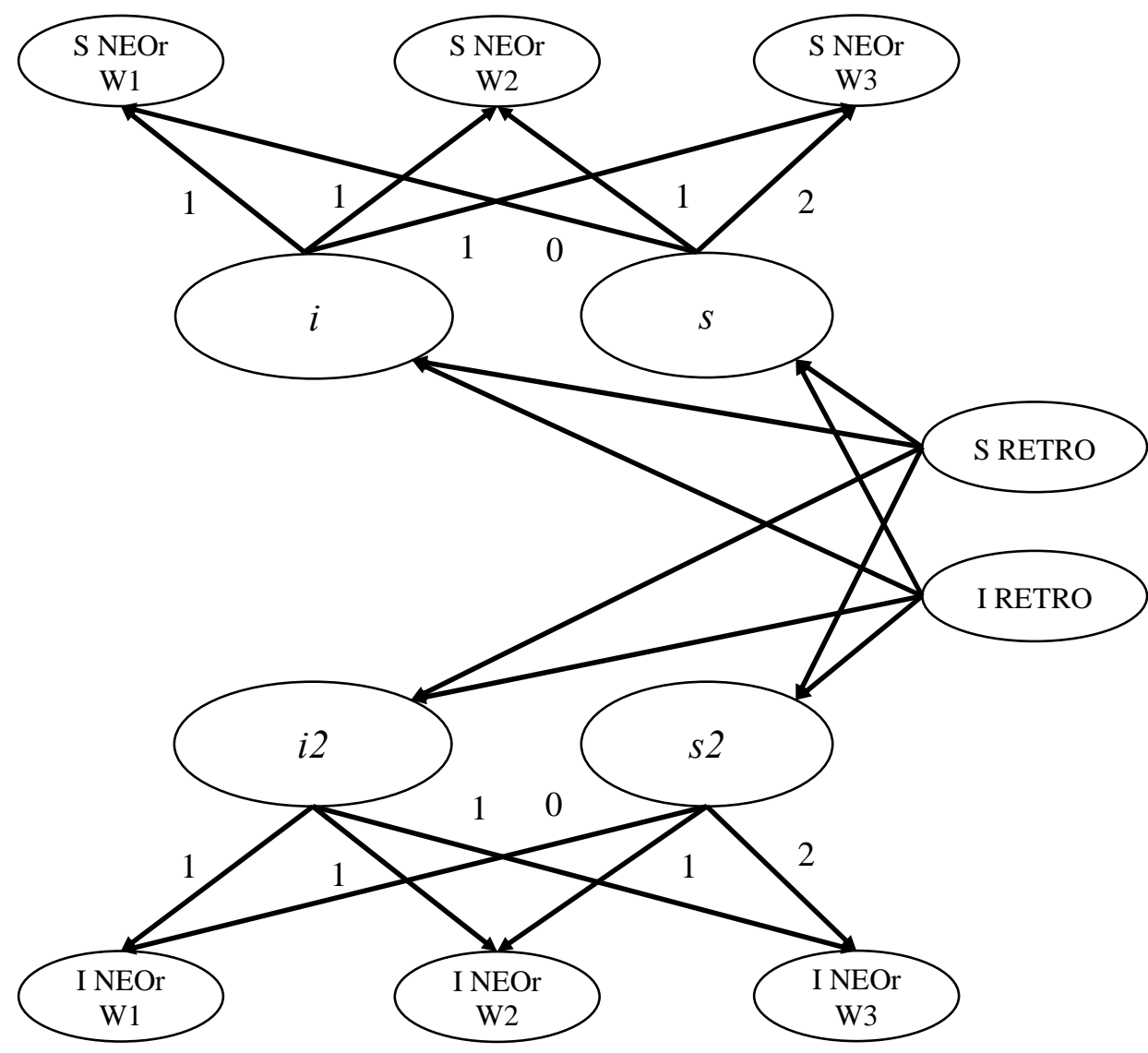

Figure 2. Bivariate latent growth model to examine convergence between longitudinal and retrospective reports of personality change. $\mathrm{S}=$ self-report, $\mathrm{I}=$ informant-report, $i=$ self-report intercept, $s=$ self-report slope, $i 2=$ informant-report intercept, $s 2=$ informant-report slope. Covariances were allowed between all four latent intercept and slope factors but are excluded from the figure for parsimony. Retro = retrospective-reports, NEOr $=$ NEO items corresponding to the retrospective items, $\mathrm{W}=$ wave. In each model, six items loaded individually onto each latent NEOr factor and latent retrospective change factor (four in the openness model). 
Appendix A

Instructions for personality change questionnaire to be rated by informants (month and year of

first assessment were added to each informant's respective questionnaire packet).

We are interested in learning about whether the person you are describing's personality traits have changed since the time that they entered our study in $\mathrm{MO}$ : YR: Enclosed are some of the same test questions that you have recently (or soon will be) filling out about this person. This time, for each item, tell us if (in your view) the person you are describing is currently the same now as they were years ago. In other words, don't tell us simply what they are like now. Rather, tell us if you think their personality has changed. And if it has, in which direction it has changed.

For example, consider the following question:

1. "She/He often feels as if she's. he's bursting with energy"

$\square$ Decreased $\square$ Slightly decreased $\square$ Stayed the same $\square$ Slightly increased $\square$ Increased

If you think that they are about the same in this regard currently as they were __ years ago, please give this a rating of "Stayed the same." If they are a little bit more like that (i.e., bursting with energy), then rate it "Slightly increased." If they are a lot more like that, rate it "Increased." On the other hand, if they are currently a little less like that than they were when they entered the study, rate it "Slightly decreased." And if they are a lot less like that than they were before, please rate it "Decreased."

Now, before you start, be sure that you have that period of time clearly in mind. The person you are describing entered our study in MO: YR: Take a minute to remember what that time was like for this person. For example, were they living in the same place that they are living now? If not, where were they living at that time? With whom were they living? Were they living with the same people they live with now? Were they working then? If so, where? Has anything else about their life changed in an important way? Thank you. 